\title{
Physicochemical, thermal and rheological properties of commercial wheat flours and corresponding starches
}

\author{
Kah Yaw EE ${ }^{1 *}$ (D), Mei Ki ENG ${ }^{1}$, Mun Ling LEE ${ }^{1}$
}

\begin{abstract}
The quality attributes, including physicochemical, thermal and rheological properties of commercial bread, pau, multipurpose and cake flours, as well as their corresponding isolated starches were analyzed. Bread flour showed the highest solvent retention capacity (SRC) and gluten performance index (GPI), suggesting better functionality than others. Starch was isolated from all types of flour and fractionated into A-type and B-type starch granules. A-type disk-like starch granule had larger diameter $(>10 \mu \mathrm{m})$ than B-type spherical starch granule $(<5 \mu \mathrm{m}$ diameter). For bread, pau and multipurpose flours, A-type starch granules contained higher amylose content than B-type and unfractionated starch granules significantly. Results suggested a high degree of crystallinity and high amount of amylose-lipid complexes in A-type starch granules, thus leading to low swelling power, solubility, gelatinization onset $\left(\mathrm{T}_{\mathrm{o}}\right)$ and peak $\left(\mathrm{T}_{\mathrm{p}}\right)$ temperatures. However, cake flour showed contrary properties, where B-type starch granules consisted higher amylose content than A-type starch granules. Furthermore, A-type and unfractionated starch granules of all types of wheat flour exhibited shear thickening behavior at $25-45^{\circ} \mathrm{C}$, but shear thinning behavior at $65^{\circ} \mathrm{C}$. The outcomes would be of benefit to the quality improvement on wheat flour with particular functionalities of their starches for specific applications.
\end{abstract}

Keywords: solvent retention capacity; amylose content; swelling power; gelatinization; rheological properties.

Practical Application: Quality assessment on wheat flour products with specific functionalities.

\section{Introduction}

Wheat (Triticum aestivum) grains are mainly used for the production of wheat flour. It provides substantial nutrients in human diet and brings huge economic benefits to the growers and manufacturers (Shewry \& Hey, 2015). Wheat flour has unique functional characteristics in food manufacturing. These characteristics are attributed to mainly two fundamental macromolecular components. Those are protein (gluten), which is responsible for forming dough into bread, and starch, which is the main non-structural carbohydrate naturally found in cereal grains. Starch is the major component of wheat kernel as it contributes $54-72 \%$ of dry weight. It is packed in endosperm as small microscopic particle which is known as starch granule (Elvers \& Ullmann, 2017). Distinct populations of starch granule lead to variation in shape, size and physicochemical properties (Pfister \& Zeeman, 2016). Wheat starch displays a bimodal starch distribution, which can be classified into A-type (large) starch granules and B-type (small) starch granules. Both types have different morphology, amylose content, relative crystallinity and microstructure, therefore leading to variation in thermal, swelling, and rheological properties (Koehler \& Wieser, 2012).

The quality and functionality of wheat flour are commonly profiled by using standardized methods. Solvent retention capacity (SRC) test is a solvation test that reveals the swelling behavior of each functional polymeric components in wheat flour, such as damaged starch, gluten protein (glutenin and gliadin) and arabinoxylan (pentosan) (Kweon et al., 2011). Besides, gluten performance index (GPI) is usually measured using the data of SRC to estimate the overall performance of gluten in wheat flour. These information are commonly used to categorize hard and soft wheat flours with different chemical and functional properties. Furthermore, the functional properties of wheat flour products can be affected by the overall proportion of two types of D-glucose polymers in the starch granules, which are amylose and amylopectin (Sramkova et al., 2009). In general, wheat starch comprises $25-28 \%$ of amylose and $72-75 \%$ of amylopectin . Amylose is a linear polysaccharide with $\alpha-(1-4)$-linked molecules with very few branch points. It is mainly found in the amorphous region of starch, which involves water absorption inhibition, plasticization of starch granules and chemical activities (Sissons, 2016). Besides, amylopectin is relatively bigger than amylose and highly branched with $\alpha$-(1-6)-linked molecules (Pérez \& Bertoft, 2010). It plays a significant role in the crystallinity of starch, which affects water insolubility, swelling properties and viscosity.

There are numerous of wheat flour products in the current market which having specific applications. However, inconsistent and limited information are available on the quality attributes. The inconsistency is most likely due to the advance in milling technology, the modification of formulation using different wheat fractions, and the use of different genotypes. In addition, 
there are very little information available on the SRC and GPI of commercial wheat flour, and morphological, swelling, thermal and rheological properties of their corresponding starches. Therefore, this study was conducted to analyze the physicochemical and quality characteristics of bread, pau, multipurpose and cake flours, and their corresponding unfractionated, A-type and B-type starches.

\section{Materials and methods}

\subsection{Materials}

Four types of commercial wheat flours, including bread, pau, multipurpose and cake flours, were sourced from local supermarket in Malaysia. All products were produced by the same local manufacturer. All reagents and chemicals were of analytical grade and purchased from Sigma Aldrich, USA; SIME Scientific, Germany; Fisher Chemical, UK; and QRëC ${ }^{\circledR}$, Singapore, unless stated otherwise.

\subsection{Solvent Retention Capacity (SRC) and Gluten Performance Index (GPI) of wheat flours}

SRC of wheat flour was determined according to the procedure of American Association for Clinical Chemistry (AACC) 56-11.02 as described in a study of Ragab \& Mohamed (2014). Four types of solvents were used in this experiment, including $5 \%(\mathrm{w} / \mathrm{w})$ of lactic acid solution, $5 \%(\mathrm{w} / \mathrm{w})$ of sodium carbonate solution, $50 \%(\mathrm{w} / \mathrm{w})$ of sucrose solution and distilled water, to examine the characteristic of glutens, damaged starch, pentosan and overall performance of flour, respectively, which contributed in the overall flour functionality and end product quality. Firstly, $5 \mathrm{~g}$ of flour sample was weighed and transferred into a $50-\mathrm{mL}$ centrifuge tube, followed by adding $25 \mathrm{~mL}$ of each diagnostic SRC solvents individually. The mixture was then mixed and vortexed in every $5 \mathrm{~min}$ for $20 \mathrm{~min}$. Next, the flour mixture was centrifuged at $1000 \mathrm{~g}$ for $15 \mathrm{~min}$. After that, the yellowish supernatant in the flour mixture was discarded and the centrifuge tube was inverted for $10 \mathrm{~min}$ to drain off the remaining solvent in the flour pallet. After that, the weight of the swollen pellet was measured and the SRC (\%) was calculated by using the formula below:

$$
\operatorname{SRC}(\%)=\left\{\left[\left(\frac{\text { pallet weight }}{\text { flour weight }}\right) \times\left(\frac{86}{100-\% \text { flour moisture }}\right)\right]-1\right\} \times 100 \%
$$

where the flour moisture (\%) was determined by using a moisture analyzer MX-50 (A\&D Company Limited, Japan).

Besides, GPI was calculated with the SRC values by using the formula below:

$$
G P I=\frac{\text { lactic acid SRC value }}{\text { sodium carbonate SRCvalue }+ \text { sucrose SRC value }}
$$

\subsection{Isolation of starch granules}

Starch granules were isolated using the suspension method described by Ačkar et al. (2010) with minor modifications. Firstly, flour was mixed with $0.25 \%(\mathrm{w} / \mathrm{v}) \mathrm{NaOH}$ solution in a ratio of 1:3 at room temperature for $1 \mathrm{~h}$. Next, the suspension was centrifuged at $1000 \mathrm{~g}$ for $5 \mathrm{~min}$ by using a bench-top centrifuge (Sartorius, Germany). After that the white precipitate was collected and washed with distilled water over a cheese cloth. The filtrate was collected and centrifuged at $1000 \mathrm{~g}$ for $5 \mathrm{~min}$. This process was repeated until the clean precipitate was obtained. The starch precipitate was then re-suspended in water and neutralized by using $1 \mathrm{M} \mathrm{HCl}$ solution, followed by centrifuge and oven drying $\left(40^{\circ} \mathrm{C}\right)$ overnight. Next, the dried starch pallets were ground into powder by using mortar and pestle. The ground sample was then passed through a mesh sieve and collected as unfractionated starch.

\subsection{Fractionation of starch granules}

The unfractionated starch was fractionated into A-type and B-type starch granules according to the method described by Zhang et al. (2013) with minor modifications. It started with mixing of $40 \mathrm{~g}$ unfractionated starch in $360 \mathrm{~mL}$ of distilled water, followed by resting at room temperature for $1 \mathrm{~h}$. After that, the upper $200 \mathrm{~mL}$ suspension was collected as B-type starch granules. Then, $200 \mathrm{~mL}$ of distilled water was added to the mixture and followed by resting for $1 \mathrm{~h}$. The above procedures were repeated until the upper suspension was clear. Then, the remaining starch sediment was collected as A-type starch granules. Both suspensions were centrifuged separately at $5000 \mathrm{~g}$ for $10 \mathrm{~min}$ and oven-dried at $40{ }^{\circ} \mathrm{C}$ overnight. After that, the dried starch pallets were ground into powder by using mortar and pestle.

\subsection{Morphology of starch granules}

The morphology of starch granules was studied using scanning electron microscope (SEM) (JEOL JSM-7610F FEG, Japan). Sample was placed onto the surface of bilateral carbon-coated adhesive tape that attached to an aluminum stub. Then, the mounted starch sample was determined with $4.0 \mathrm{kV}$ accelerating voltage, $10 \mathrm{~A}$ emission current, $6 \mathrm{~mm}$ working distance, and 1000 times magnification.

\subsection{Amylose content determination}

The amylose content in starch granules was analyzed according to the method as described in a study of Jan et al. (2016) with minor modifications. Firstly, $70 \mathrm{mg}$ of starch was dissolved in $10 \mathrm{~mL}$ of UDMSO solution (a mixture of $0.6 \mathrm{M}$ urea and $90 \%$ DMSO in 1:9 ratio) in a screw-cap test tube. Then, the sample solution was heated at $100^{\circ} \mathrm{C}$ in a water bath (Memmert, Germany) for $10 \mathrm{~min}$ with continuous shaking and regularly inversion to prevent precipitation. After that, the sample was incubated in the water bath for another $1 \mathrm{~h}$. After cooling to room temperature, $0.5 \mathrm{~mL}$ of the sample was mixed with $25 \mathrm{~mL}$ of distilled water and $2 \mathrm{~mL}$ of $0.01 \mathrm{~N}$ iodine-potassium iodide solution (a mixture of $1.27 \mathrm{~g} / \mathrm{L}$ iodine solution and $3 \mathrm{~g} / \mathrm{L}$ potassium iodide solution). The absorbance (blue value) was read at wavelength $635 \mathrm{~nm}$ by using a UV-Vis spectrophotometer (Thermo Fisher Scientific, USA). A blank sample was prepared by using $10 \mathrm{~mL}$ of UDMSO without starch sample. The amylose content was calculated by using the formula below:

Amylose content $=(28.414 \times$ blue value $)-6.218$ 


\subsection{Swelling power, swelling volume and solubility index of starch granules}

The swelling and solubility properties of starch granules were determined according to the procedures described in a study of Eriksson et al. (2014) with minor modifications. One gram of starch granule was added with distilled water to a total volume of $40 \mathrm{~mL}$ in a $50-\mathrm{mL}$ centrifuge tube. It was then shaken gently and heated at $85{ }^{\circ} \mathrm{C}$ in a water bath (Memmert, Germany) for 30 min with continuous shaking. After heating, the centrifuge tube was cooled to room temperature and centrifuged at $520 \mathrm{~g}$ for $15 \mathrm{~min}$. Next, the supernatant was transferred onto a pan and oven-dried at $105^{\circ} \mathrm{C}$ for $4 \mathrm{~h}$. The weight of the dried residue (DR) and the sediment paste (SP) were obtained to calculate swelling power $(\mathrm{g} / \mathrm{g})$ and solubility (\%) using the formulas as below. Swelling volume $(\mathrm{mL})$ was measured directly from the height of the sediment in tube.

$$
\begin{aligned}
& \text { Swelling power }=\frac{S P}{1 g-D R} \\
& \text { Solubility }=\frac{D R(g)}{\lg } \times 100 \%
\end{aligned}
$$

\subsection{Thermal properties of starch gelatinization}

Thermal properties of starch gelatinization was analyzed following the method of Ačkar et al. (2010) using a differential scanning calorimeter DSC 822e (Mettler Toledo, USA) which was equipped with STARe software. Starch sample (3 mg) was weighed into a $40-\mu \mathrm{L}$ aluminum crucible (ME-27331), followed by adding $9 \mu \mathrm{L}$ of distilled water to achieve 1:3 ratio. Then, the aluminum crucible was sealed hermetically and equilibrated at room temperature for $24 \mathrm{~h}$ before the analysis. The thermal analysis was carried out with a heating rate of $10{ }^{\circ} \mathrm{C} / \mathrm{min}$ from $25{ }^{\circ} \mathrm{C}$ to $100{ }^{\circ} \mathrm{C}$. The onset $\left(\mathrm{T}_{\mathrm{o}}\right)$, peak $\left(\mathrm{T}_{\mathrm{p}}\right)$ and conclusion $\left(\mathrm{T}_{\mathrm{c}}\right.$ ) temperatures were obtained from a DSC thermogram.

\subsection{Rheological properties of starch granules}

The flow behavior and viscosity of starch granules were studied referring to the method of Barrera et al. (2013) with some modifications using a Discovery HR-1 Rheometer (TA Instruments, USA) which was equipped with TRIOS software, a compressor, and nitrogen gas. Starch sample was suspended in distilled water $(20 \% \mathrm{w} / \mathrm{w})$ and stirred for at least
$3 \mathrm{~h}$. The rheological test was started with the calibration of geometry gap by setting the gap to zero. After that, an aliquot $(\approx 1 \mathrm{~mL})$ of starch suspension was loaded on the bottom plate with care by using a dropper to avoid air bubble and equilibrated at $25^{\circ} \mathrm{C}, 45^{\circ} \mathrm{C}$ and $65^{\circ} \mathrm{C}$, individually. Next, the gap was set to trim gap and the overloaded starch sample was scraped away with care. The measurement was started after the geometry gap was set to $0.5 \mathrm{~mm}$. The $40-\mathrm{mm}$ steel plate geometry was accelerated uniformly from $0 \mathrm{~s}^{-1}$ to $300 \mathrm{~s}^{-1}$ in $3 \mathrm{~min}$ and the shear rate was kept constant for $10 \mathrm{~min}$, followed by decelerating uniformly from $300 \mathrm{~s}^{-1}$ to $0 \mathrm{~s}^{-1}$ in 3 min. Lastly, a rheological flow curve was generated and the Power-Law model was applied onto the decelerating curve to characterize the flow behavior. The formula below is the Power-Law model:

$\tau=K \gamma^{n}$

where $\tau=$ shear stress $(\mathrm{Pa}), \mathrm{K}=$ consistency index (Pa.s), $\gamma=$ shear rate $\left(\mathrm{s}^{-1}\right)$ and $\mathrm{n}=$ flow behavior index.

\subsection{Statistical Analysis}

All analyses were conducted in triplicates and results were reported in mean and standard deviation. ANOVA, t-test and Tukey HSD test were employed to analyze data using SPSS software, where significant differences were reported at $\mathrm{p}<0.05$.

\section{Results and discussion}

\subsection{Solvent Retention Capacity (SRC) of wheat flours}

Table 1 shows the solvent retention capacities of bread, pau, multipurpose and cake flours. Solvent retention capacity test is a fast and inexpensive assay to evaluate the quality and functionality profile of wheat flour. The lactic acid value reflected the protein content, functionality of gluten and characteristics of glutenin. High lactic acid values in bread and pau flours suggested that both had high protein level and functionality. Similar studies (Xiao et al., 2006; Lindgren \& Simsek, 2015) also reported that lactic acid value showed linear correlation with protein content of wheat and capability to differentiate the quality of wheat flour. Besides, gluten content relates to the development of dough while glutenin imparts the strength and elasticity of dough, which both components are correlated to the loaf volume (Dhaka \& Khatkar, 2015). Multipurpose flour was also considered as a hard wheat flour, but with lower

Table 1. Solvent retention capacity (SRC) of wheat flours.

\begin{tabular}{ccccc}
\hline \multirow{2}{*}{ Types of flour } & \multicolumn{4}{c}{ Solvent retention capacity $(\%)^{*}$} \\
\cline { 2 - 5 } & $5 \%(\mathrm{w} / \mathrm{w})$ lactic acid & $5 \%(\mathrm{w} / \mathrm{w})$ sodium carbonate & $50 \%(\mathrm{w} / \mathrm{w})$ sucrose & Distilled water \\
\hline Bread & $125.63 \pm 3.68^{\mathrm{A}, \mathrm{a}}$ & $100.38 \pm 1.51^{\mathrm{A}, \mathrm{b}}$ & $88.86 \pm 0.88^{\mathrm{A}, \mathrm{c}}$ & $72.81 \pm 1.29^{\mathrm{A}, \mathrm{d}}$ \\
Pau & $113.19 \pm 3.01^{\mathrm{B}, \mathrm{a}}$ & $98.51 \pm 4.12^{\mathrm{A}, \mathrm{b}}$ & $88.33 \pm 1.38^{\mathrm{A}, \mathrm{c}}$ & $69.95 \pm 1.92^{\mathrm{A}, \mathrm{d}}$ \\
Multipurpose & $108.76 \pm 2.09^{\mathrm{C}, \mathrm{a}}$ & $84.61 \pm 1.99^{\mathrm{B}, \mathrm{b}}$ & $96.68 \pm 2.24^{\mathrm{B}, \mathrm{c}}$ & $70.55 \pm 2.36^{\mathrm{A}, \mathrm{d}}$ \\
Cake & $75.06 \pm 1.90^{\mathrm{D}, \mathrm{a}}$ & $85.50 \pm 0.06^{\mathrm{B}, \mathrm{b}}$ & $90.55 \pm 1.59^{\mathrm{C}, \mathrm{c}}$ & $65.14 \pm 1.88^{\mathrm{B}, \mathrm{d}}$ \\
\hline
\end{tabular}

${ }^{*}$ Data are means of three determinations with standard deviations. ${ }^{\mathrm{A}-\mathrm{D}}$ Data in column and ${ }^{\mathrm{a}-\mathrm{d}}$ data in row with the same superscripts are not significantly different while data with different superscripts are significant different $(\mathrm{p}<0.05)$. 
protein content than bread and pau flours. Therefore, it served for all purposes, such as making cakes, biscuits, noodles, pau and many others. However, it would result in a slightly coarse texture and lower volume compared to using soft wheat flour. Cake flour had the lowest gluten content among all samples, was categorized as soft wheat flour and suitable for making fine, smooth and soft texture products.

Besides, high sodium carbonate values in bread and pau flours indicated that both had high levels of damaged starch. A study of Khan et al. (2015) reported that hard wheat flour contained more damaged starch granules due to higher pressure and force were required in milling process. Damaged starch granules are easily hydrated in the presence of solvent to form sticky dough, strong proofing, low loaf volume and increased crumb hardness which are undesirable for bread and pau (Ghodke et al., 2009; Dhaka \& Khatkar, 2015). Apart from milling techniques, other factors, such as type of wheat, amount of water added in tempering, temperature of rolls, can affect the amount of damaged starch (Dhaka \& Khatkar, 2015). Lower amount of damaged starch in multipurpose flour could be recommended for making bread and pau, but the lower protein level might affect the rheological properties of the products.

The value of sucrose solution acts as an indicator of the pentosan content in flours (Kweon et al., 2011). Pentosan is known as a non-starch polysaccharide that effects on the end-use of wheat quality (Saeed et al., 2014). It enhances water absorption and holding capacity of dough, especially at low $\mathrm{pH}$, thus improving the development and shaping of dough and extending its stability time (Saeed et al., 2014). However, results showed both bread and pau flours had lower sucrose solution values than multipurpose and cake flours. In fact, higher pentosan content is required in hard wheat flours for the production of bread and pau, however, it is an undesirable property for good quality cake flour. Furthermore, distilled water was used as a reference SRC solvent due to its ability to hydrate and swell all the functional flour components to different extents (Kweon et al., 2011).

\subsection{Gluten Performance Index (GPI)}

Table 2 shows gluten performance index of bread, pau, multipurpose and cake flours. As expected, bread flour had the highest GPI among all the samples but it was not significantly $(p>0.05)$ different with pau flour. It was then followed by multipurpose flour and cake flour. GPI has been an excellent indicator of the overall performance of gluten in the environment that modulating networks of flour polymers. For instance, it was

Table 2. Gluten performance index of wheat flours.

\begin{tabular}{cc}
\hline Types of flour & Gluten performance index ${ }^{*}$ \\
\hline Bread & $0.66 \pm 0.02^{\mathrm{a}}$ \\
Pau & $0.61 \pm 0.04^{\mathrm{a}}$ \\
Multipurpose & $0.55 \pm 0.01^{\mathrm{b}}$ \\
Cake & $0.46 \pm 0.02^{\mathrm{c}}$ \\
\hline
\end{tabular}

${ }^{*}$ Data are means of three determinations with standard deviations. ${ }^{\mathrm{a}-\mathrm{c}} \mathrm{Data}$ in column same superscripts are not significantly different while data with different superscripts are significant different $(\mathrm{p}<0.05)$. used to determine the quality of flour during baking process, especially for bread. It is directly proportional to lactic acid SRC value (Kweon et al., 2011). Results agreed that the lactic acid SRC value had an inversely proportional relationship with sodium carbonate and sucrose SRC values (Lindgren \& Simsek, 2015), where a high lactic acid SRC value in combination with low sodium carbonate and sucrose SRC values represent a good overall performance of gluten. Low GPI in cake flour was mainly due to lacking of protein content (Table 1).

\subsection{Morphology of wheat starch}

Figure 1 shows that all the wheat starch granules are spherical or oval in shape. The unfractionated starch granules were the combination of A-type and B-type starch granules. The micrograph revealed that A-type starch granules exhibited a disc-liked shape with larger diameter of more than $10 \mu \mathrm{m}$, whereas B-type starch granules displayed a spherical shape with diameter of less than $5 \mu \mathrm{m}$. Similar studies of Zeng et al. (2011) and Zhang et al. (2016) also reported that A-type starch granules had a greater diameter $(10-30 \mu \mathrm{m})$ than B-type starch granules (approximately $5 \mu \mathrm{m}$ ). Furthermore, it has been reported that B-type starch granules existed predominantly in wheat, however, A-type starch contributed more than $70 \%$ of the total weight and volume percentage (Zeng et al., 2011; Zhang et al., 2013; Zhang et al., 2016). The morphology of starch granules could vary with the genotype, the biochemistry of the chloroplast or amyloplast, and the cultural practices (Yin \& Wang, 2016). The differences in morphology are significantly correlated with the variation of their physicochemical properties, such as amylose content, swelling power, solubility index and water holding capacity (Yin \& Wang, 2016). For instance, small granules were suggested to be used in food, cosmetic and medicinal industries as fat substitutes, stabilizers, biodegradable films and other applications, due to their higher water absorption capacity (Sarker et al., 2012).

\subsection{Amylose content in starch granules}

Among all type of starch granules, A-type starch granules showed the highest amylose content whereas B-type starch granules had the lowest amount, except cake flour (Figure 2). All unfractionated starch samples had similar amount of amylose, ranged from $21.68-23.93 \%$. For A-type starch granules, the highest amount of amylose content was found in pau $(32.48 \pm 0.15 \%)$ flour, followed by bread $(26.13 \pm 0.23 \%)$, multipurpose $(26.08 \pm 0.22 \%)$ and cake $(20.79 \pm 0.33 \%)$ flours. For B-type starch, cake flour had the highest amount of amylose content $(31.96 \pm 0.11 \%)$, followed by multipurpose $(21.67 \pm 0.33 \%)$, pau $(14.35 \pm 0.48 \%)$ and bread $(13.80 \pm 0.30 \%)$ flours. Results were in agreement with similar studies of Li et al. (2013), Zhang et al. (2016) and Shevkani et al. (2016) on different cultivars of wheat starch, which suggested that B-type starch granules had higher ratio of amylopectin to amylose. Amylose content plays a vital role in production of baked products to prevent collapse during cooling process, especially bread. Low amylose content will reduce the dough stickiness and elasticity, resulted in higher water absorption of starch and gluten, higher gas formation, bigger loaf volume but lower gas retention coefficient, reduced in staling and improved 

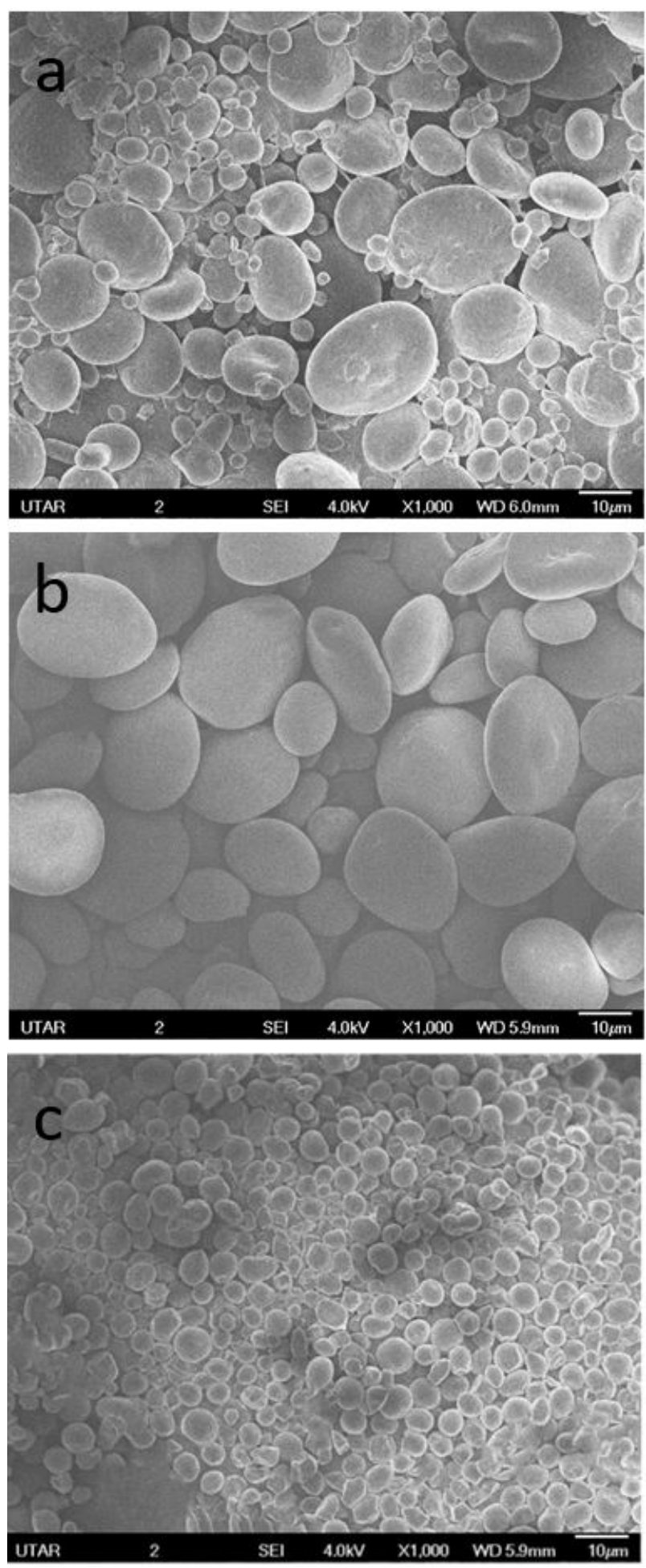

Figure 1. Representative scanning electron micrographs of (a) unfractionated, (b) A-type and (c) B-type starch granules. Scale bar $=10 \mu \mathrm{m}$; Magnifying power $=x 1000$.

crumb texture of baked products (Lee et al., 2001; Alcázar-Alay \& Meireles, 2015). The variation in amylose content might be due to the hereditary, variation in wheat culture, growing environments, botanical sources, harvesting period and type of soil (Noda et al., 2004; Wickramasinghe et al., 2005).

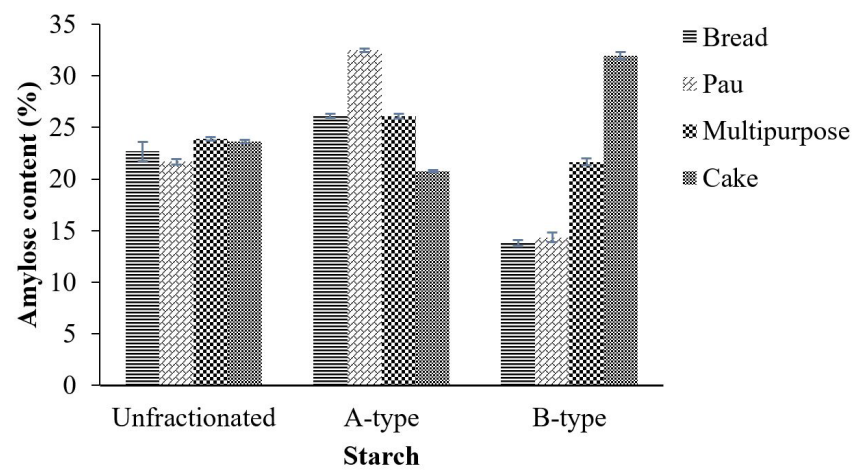

Figure 2. Amylose content of unfractionated, A-type and B-type starches in different types of wheat flour.

\subsection{Swelling properties of starch granules}

Table 3 shows the swelling power, solubility and swelling volume of starch granules from different wheat flours. Other than cake flour, all B-type starch granules had the highest swelling power and solubility, and all A-type starch granules had the lowest swelling volume. Swelling test measures the water uptake during the starch gelatinization. The higher the water uptake, the higher the swelling power. When starch granules are heated in excess water, their crystalline and amorphous structures are disrupted and the water molecules bind to the exposed hydroxyl group of amylose and amylopectin (Oh et al., 2008). However, several studies claimed that amylose acted as swelling inhibitor, with or without the presence of lipids (Hoover, 2001; Noranizan et al., 2010; Oke et al., 2013; Zhang et al., 2017). Amylose tends to hold back swelling and maintain the integrity of swollen granules. In the presence of amylose-lipid complexes, they restricted granular swelling and amylose leaching, hence decreased swelling power (Hasjim et al., 2013). This was evidenced in B-type starch granules of cake flour in present study with higher amylose content (Figure 2) and lower swelling power (Table 3).

Furthermore, solubility of starch granules reflects the amount of amylose leach out from granules into water after heating. The higher the amylose content in starch granules, the more compact it is. In this case, the mobility of amylose is lowered and the overflowing to outer of starch granules is restricted. Besides, this increases the possibility of the formation of amylose-lipid complexes, thus leading to low solubility (Wani et al., 2013; Eriksson et al., 2014). This was evidenced in A-type starch granules of bread, pau and multipurpose flours (Table 3 ) in present study.

Moreover, a similar study of Marta \& Tensiska (2017) suggested that low swelling volume could be attributed to the strong interaction between amylose and amylopectin which resulted rigid starch granules after heat treatment. This was observed in A-type starch granules of bread, pau and multipurpose flour. For cake flour, swelling volume of A-type and B-type starch granules was not significantly different $(p>0.05)$ but slightly higher than the unfractionated starch granules. These results were in consistent with the results that reported in similar studies of Yu et al. (2010), Zhang et al. (2012), Oke et al. (2013) and Achor et al. (2015). Overall, the swelling characteristics of starch granules can be 
Table 3. Swelling power, solubility and swelling volume of starch granules.

\begin{tabular}{|c|c|c|c|c|}
\hline Types of flour & Starch granule & Swelling power $(\mathrm{g} / \mathrm{g})^{\star}$ & Solubility $(\%)^{*}$ & Swelling volume $(\mathrm{mL})^{\star}$ \\
\hline \multirow[t]{3}{*}{ Bread } & Unfractionated & $7.70 \pm 0.31^{\mathrm{a}}$ & $2.66 \pm 0.47^{\mathrm{a}}$ & $15.67 \pm 0.67^{\mathrm{a}}$ \\
\hline & A-type & $5.82 \pm 0.11^{\mathrm{b}}$ & $3.41 \pm 0.07^{\mathrm{b}}$ & $13.33 \pm 0.67^{\mathrm{b}}$ \\
\hline & B-type & $8.06 \pm 0.17^{\mathrm{a}}$ & $3.87 \pm 0.25^{\mathrm{c}}$ & $15.67 \pm 0.67^{\mathrm{a}}$ \\
\hline \multirow{2}{*}{ Pau } & A-type & $6.80 \pm 0.19^{c}$ & $4.72 \pm 0.24^{\mathrm{e}}$ & $15.67 \pm 0.34^{\mathrm{a}}$ \\
\hline & B-type & $8.81 \pm 0.19^{\mathrm{d}}$ & $7.30 \pm 0.09^{\mathrm{f}}$ & $16.44 \pm 0.77^{c}$ \\
\hline Multipurpose & B-type & $11.36 \pm 0.72^{\mathrm{e}}$ & $3.60 \pm 0.40^{c}$ & $15.44 \pm 0.19^{\mathrm{a}}$ \\
\hline \multirow[t]{3}{*}{ Cake } & Unfractionated & $8.74 \pm 0.32^{\mathrm{a}}$ & $4.61 \pm 0.20^{\mathrm{e}}$ & $13.33 \pm 0.58^{\mathrm{b}}$ \\
\hline & A-type & $9.20 \pm 0.29^{d}$ & $4.64 \pm 0.65^{\mathrm{e}}$ & $14.44 \pm 0.51^{\mathrm{e}}$ \\
\hline & B-type & $8.02 \pm 0.28^{\mathrm{a}}$ & $2.35 \pm 0.15^{\mathrm{a}}$ & $14.55 \pm 0.77^{\mathrm{e}}$ \\
\hline
\end{tabular}

${ }^{*}$ Data are means of three determinations with standard deviations. ${ }^{a-f}$ Data in column with the same superscripts are not significantly different while data with different superscripts are significant different $(\mathrm{p}<0.05)$.

affected by many factors, such as genotype, cultural practices, botanical sources, components in starch granules, ratio of types of granules and heating conditions (Yin \& Wang, 2016).

\subsection{Gelatinization properties of starch granules}

Gelatinization is an irreversible reaction of starch when the starch is heated with excess water (Kawai et al., 2012). Hydration and destabilization of hydrogen bonds in starch amorphous regions leads to the loss of starch crystallinity and change of molecular structure. Gelatinization temperature refers to the temperature when the order of starch molecules is disrupted and the crystallites start to melt (Horstmann et al., 2017). Table 4 shows the gelatinization parameters, including onset $\left(\mathrm{T}_{\mathrm{o}}\right.$ ), peak $\left(\mathrm{T}_{\mathrm{p}}\right)$ and conclusion $\left(\mathrm{T}_{\mathrm{c}}\right)$ temperatures, of unfractionated, A-type and B-type starch granules of different types of wheat flour. Unfractionated starch granules of all flour samples had generally higher $\mathrm{T}_{\mathrm{o}}, \mathrm{T}_{\mathrm{p}}$ and $\mathrm{T}_{\mathrm{c}}$ compared to A-type and B-type starch granules, except the $\mathrm{T}_{\mathrm{p}}$ and $\mathrm{T}_{\mathrm{c}}$ values for bread and cake flours. For bread, pau and multipurpose flours, A-type starch granules had slightly higher $\mathrm{T}_{\mathrm{o}}$ and $\mathrm{T}_{\mathrm{p}}$, but lower $\mathrm{T}_{\mathrm{c}}$ compared to B-type starch granules. Results were in agreement with studies of Kim \& Huber (2010) and Zhang et al. (2016). This phenomenon was due to higher degree of crystallinity, short-range order and higher number of intramolecular hydrogen bonds at carbon-6 of A-type granules (Zhang et al., 2013). A higher degree of crystallinity caused the accumulation of crystalline defect during starch deposition and thus exhibited at a shorter gelatinization temperature range (Bocharnikova et al., 2003). Besides, the presence of amylose-lipid complexes could be another factor of low degree of gelatinization because they required a higher temperature ( $\mathrm{T}_{\mathrm{o}}$ ) to melt (Thachil et al., 2013). Furthermore, lower $\mathrm{T}_{\mathrm{o}}$ of B-type starch granules were mostly due to low water uptake during early gelatinization stage, as early gelatinization could occur when water uptake was more than 30\% (Ratnayake et al., 2009).

On the other hand, the higher $\mathrm{T}_{c}$ of B-type starch granules indicated a longer gelatinization temperature range compared to A-type starch granules. This was due to a lower gelatinization initiation temperature $\left(\mathrm{T}_{\mathrm{o}}\right)$ in B-type starch granules than A-type starch granules. The long gelatinization range revealed that B-type starch granules were in large number of granules per weight and contained large proportion of short amylopectin chain (degree of polymerization $<8$ ) which could form strong and long double helices. These long double helices provide stability to the crystalline lamellae and increase in overall density. A crystalline lamella with higher density able to withstand higher gelatinization temperature $\left(>64^{\circ} \mathrm{C}\right)$ without structure disruption (Vermeylen et al., 2005; Waterschoot et al., 2014). In contrast, for cake flour, B-type starch granules had higher $\mathrm{T}_{\mathrm{o}}, \mathrm{T}_{\mathrm{p}}$ and $\mathrm{T}_{\mathrm{c}}$ than A-type starch granules. This could be mainly due to the higher amount of amylose content (Figure 2) in B-type starch granules, and other factors, such as moisture content, amylose-lipid complexes and experiment setting (Vermeylen et al., 2005).

\subsection{Rheological properties of starch granules}

The rheological characteristic of starch is associated with the change of its viscosity with the change of temperature, concentration and shear rate or stress. Apart from that, the structure and morphology of starch granules as well as the presence of other components will also affect the rheological properties of starch (Alcázar-Alay \& Meireles, 2015; Ahmadi-Abhari et al., 2015). The Power Law model (Ostwald-de Waele's model) was applied to obtain the consistency index (viscosity) and flow behavior of unfractionated and A-type starch granules (Table 5). This study did not apply to B-type starch granules due to limitation of sample quantity. All results achieved high coefficient of determination, which were above 0.97 , in order to ensure the accuracy and precision of the data. Results showed that the viscosity of starch, under same shear stress, increased with the increase of temperature from $25^{\circ} \mathrm{C}$ to $65^{\circ} \mathrm{C}$. Besides, all starch granules exhibited similar flow behavior at $25{ }^{\circ} \mathrm{C}$ and $45{ }^{\circ} \mathrm{C}$ and showed a sharp decrease from $45^{\circ} \mathrm{C}$ to $65^{\circ} \mathrm{C}$. The flow characteristics of starch granules were determined with shear thinning (pseudoplastic) when $\mathrm{n}>1$ and shear thickening (dilatant) when $\mathrm{n}<1$. Results were in agreement with similar studies of Gupta et al. (2009), Ratnayake et al. (2009), Barrera et al. (2013), Ai \& Jane (2015). They reported that during the early 
Table 4. Gelatinization parameters $\left(\mathrm{T}_{\mathrm{o}}, \mathrm{T}_{\mathrm{p}}\right.$ and $\left.\mathrm{T}_{\mathrm{c}}\right)$ of starch granules.

\begin{tabular}{|c|c|c|c|c|}
\hline Types of flour & Starch granules & Onset temperature, $\mathrm{T}_{\mathrm{o}}\left({ }^{\circ} \mathrm{C}\right)^{*}$ & Peak temperature, $\mathrm{T}_{\mathrm{p}}\left({ }^{\circ} \mathrm{C}\right)^{*}$ & $\begin{array}{c}\text { Conclusion temperature, } \\
\mathrm{T}_{\mathrm{c}}\left({ }^{\circ} \mathrm{C}\right)^{*}\end{array}$ \\
\hline \multirow[t]{3}{*}{ Bread } & Unfractionated & $57.05 \pm 0.29^{\mathrm{a}}$ & $61.00 \pm 0.00^{\mathrm{a}}$ & $65.77 \pm 0.51^{\mathrm{a}}$ \\
\hline & A-type & $56.96 \pm 0.12^{\mathrm{a}}$ & $61.50 \pm 0.47^{\mathrm{a}}$ & $65.69 \pm 0.17^{\mathrm{a}}$ \\
\hline & B-type & $56.04 \pm 0.15^{\mathrm{b}}$ & $60.67 \pm 0.17^{\mathrm{a}}$ & $67.09 \pm 0.17^{\mathrm{b}}$ \\
\hline \multirow[t]{3}{*}{$\mathrm{Pau}$} & Unfractionated & $57.42 \pm 0.06^{\mathrm{a}}$ & $61.56 \pm 0.57^{\mathrm{a}}$ & $65.74 \pm 0.79^{a}$ \\
\hline & A-type & $56.44 \pm 0.35^{\mathrm{a}}$ & $60.58 \pm 0.35^{\mathrm{a}}$ & $64.82 \pm 0.78^{\mathrm{a}}$ \\
\hline & B-type & $55.54 \pm 0.07^{c}$ & $60.17 \pm 0.50^{\mathrm{a}}$ & $65.43 \pm 0.25^{\mathrm{a}}$ \\
\hline \multirow[t]{3}{*}{ Multipurpose } & Unfractionated & $59.74 \pm 0.24^{\mathrm{d}}$ & $64.67 \pm 0.17^{b}$ & $70.17 \pm 0.56^{c}$ \\
\hline & A-type & $57.85 \pm 0.54^{\mathrm{a}}$ & $61.95 \pm 0.39^{\mathrm{a}}$ & $66.80 \pm 0.12^{\mathrm{b}}$ \\
\hline & B-type & $55.17 \pm 0.68^{c}$ & $61.56 \pm 0.54^{\mathrm{a}}$ & $67.17 \pm 0.15^{\mathrm{b}}$ \\
\hline \multirow[t]{3}{*}{ Cake } & Unfractionated & $58.95 \pm 0.32^{\mathrm{e}}$ & $63.45 \pm 0.25^{c}$ & $68.07 \pm 0.54^{\mathrm{b}}$ \\
\hline & A-type & $57.28 \pm 0.06^{\mathrm{a}}$ & $61.39 \pm 0.10^{\mathrm{a}}$ & $66.51 \pm 0.16^{\mathrm{a}}$ \\
\hline & B-type & $58.34 \pm 0.46^{\mathrm{e}}$ & $65.78 \pm 0.48^{\mathrm{d}}$ & $71.46 \pm 0.40^{c}$ \\
\hline
\end{tabular}

${ }^{*}$ Data are means of three determinations with standard deviations. ${ }^{a-e}$ Data in column with the same superscripts are not significantly different while data with different superscripts are significant different $(\mathrm{p}<0.05)$.

Table 5. The Power Law parameters of starch granules at different temperatures.

\begin{tabular}{|c|c|c|c|c|c|}
\hline \multirow{2}{*}{ Types of flour } & \multirow{2}{*}{ Temperature $\left({ }^{\circ} \mathrm{C}\right)$} & \multicolumn{2}{|c|}{ Consistency index, $\mathrm{K}(\mathrm{Pa} . \mathrm{s})^{*}$} & \multicolumn{2}{|c|}{ Flow behaviour, $\mathrm{n}^{\star}$} \\
\hline & & Unfractionated starch & A-type starch & Unfractionated starch & A-type starch \\
\hline \multirow[t]{3}{*}{ Bread } & 25 & $0.0009 \pm 0.0001^{\mathrm{a}}$ & $0.0009 \pm 0.0001^{\mathrm{a}}$ & $1.21 \pm 0.05^{\mathrm{a}}$ & $1.19 \pm 0.03^{\mathrm{a}}$ \\
\hline & 45 & $0.0008 \pm 0.0006^{\mathrm{a}}$ & $0.0008 \pm 0.0004^{\mathrm{a}}$ & $1.28 \pm 0.14^{\mathrm{a}}$ & $1.21 \pm 0.15^{\mathrm{a}}$ \\
\hline & 65 & $93.2405 \pm 16.5293^{\mathrm{b}}$ & $113.6470 \pm 11.7631^{\mathrm{b}}$ & $0.37 \pm 0.03^{b}$ & $0.37 \pm 0.04^{\mathrm{b}}$ \\
\hline \multirow[t]{3}{*}{ Pau } & 25 & $0.0008 \pm 0.0000^{\mathrm{a}}$ & $0.0019 \pm 0.0013^{\mathrm{a}}$ & $1.26 \pm 0.03^{\mathrm{a}}$ & $1.17 \pm 0.06^{\mathrm{a}}$ \\
\hline & 45 & $0.0004 \pm 0.0003^{\mathrm{a}}$ & $0.0007 \pm 0.0001^{\mathrm{a}}$ & $1.36 \pm 0.10^{\mathrm{a}}$ & $1.27 \pm 0.01^{\mathrm{a}}$ \\
\hline & 65 & $146.2423 \pm 12.8994^{c}$ & $143.5950 \pm 15.0566^{\mathrm{c}}$ & $0.46 \pm 0.02^{c}$ & $0.34 \pm 0.02^{b}$ \\
\hline \multirow[t]{3}{*}{ Multipurpose } & 25 & $0.0014 \pm 0.0000^{\mathrm{a}}$ & $0.0019 \pm 0.0000^{\mathrm{a}}$ & $1.24 \pm 0.04^{\mathrm{a}}$ & $1.17 \pm 0.03^{\mathrm{a}}$ \\
\hline & 45 & $0.0015 \pm 0.0000^{\mathrm{a}}$ & $0.0008 \pm 0.0000^{\mathrm{a}}$ & $1.25 \pm 0.02^{\mathrm{a}}$ & $1.24 \pm 0.08^{\mathrm{a}}$ \\
\hline & 65 & $139.0617 \pm 19.4650^{c}$ & $148.0108 \pm 10.4500^{c}$ & $0.39 \pm 0.04^{\mathrm{b}}$ & $0.40 \pm 0.04^{b}$ \\
\hline \multirow[t]{3}{*}{ Cake } & 25 & $0.0012 \pm 0.0000^{\mathrm{a}}$ & $0.0011 \pm 0.0000^{\mathrm{a}}$ & $1.19 \pm 0.01^{\mathrm{a}}$ & $1.24 \pm 0.02^{\mathrm{a}}$ \\
\hline & 45 & $0.0022 \pm 0.0000^{\mathrm{a}}$ & $0.0013 \pm 0.0000^{\mathrm{a}}$ & $1.21 \pm 0.07^{\mathrm{a}}$ & $1.19 \pm 0.06^{\mathrm{a}}$ \\
\hline & 65 & $154.6702 \pm 17.9020^{\mathrm{d}}$ & $185.3512 \pm 88.3406^{\mathrm{d}}$ & $0.36 \pm 0.01^{\mathrm{b}}$ & $0.33 \pm 0.05^{b}$ \\
\hline
\end{tabular}

${ }^{*}$ Data are means of three determinations with standard deviations; ${ }^{\text {a-d } D a t a ~ i n ~ c o l u m n ~ w i t h ~ t h e ~ s a m e ~ s u p e r s c r i p t s ~ a r e ~ n o t ~ s i g n i f i c a n t l y ~ d i f f e r e n t ~ w h i l e ~ d a t a ~ w i t h ~ d i f f e r e n t ~ s u p e r s c r i p t s ~}$ are significant different $(\mathrm{p}<0.05)$.

gelatinization stages $\left(25-45^{\circ} \mathrm{C}\right)$, starch granules had a similar flow behavior. When starch suspension was heated beyond its gelatinization temperature $\left(64^{\circ} \mathrm{C}\right)$, the starch granules started to swell and the viscosity of starch increased until a maximum level. Continuous heating with shearing caused the weakening and shear damage (disruption) of starch granules, as well as leaching of starch components. Overall, the viscosity of starch granules is directly proportional to the temperature while inversely proportional to the flow behavior.

\section{Conclusions}

In summary, the morphological, thermal and physicochemical properties of four commercial wheat flours were reported and their quality attributes were discussed. The shape and size of unfractionated, A-type and B-type starch granules were observed in SEM. In general, bread flour showed the highest lactic acid SRC and GPI values among all samples. This strongly suggested that bread flour had a higher glutenin content and greater functionality than others. Furthermore, the difference of amylose content in starch granules caused significant impact on the physicochemical, thermal and rheological properties. A-type starch granules of bread, pau and multipurpose flours contained relatively higher amylose content, thus exhibiting lower swelling power and shorter gelatinization temperature range than B-type starch granules. On the other hand, A-type and B-type starch granules of cake flour showed contrary properties. Furthermore, all types of starch exhibited shear thinning behavior when temperature raised to gelatinization temperature $\left(65^{\circ} \mathrm{C}\right)$. In general, all types of wheat flour exhibited considerable adequate quality attributes. The outcomes provided fundamental understanding on the characteristics of starch in different types of wheat flour and aided future investigation on the structure-function relationships of starch granules, as well as food product development.

\section{Acknowledgement}

This research was financially supported by Faculty of Science, Universiti Tunku Abdul Rahman, Malaysia. 


\section{References}

Achor, M., Oyeniyi, J., Musa, M., \& Gwarzo, M. (2015). Physicochemical properties of cassava starch retrograded in alcohol. Journal of Applied Pharmaceutical Science, 5(10), 126-131. http://dx.doi.org/10.7324/ JAPS.2015.501021.

Ačkar, Đ., Babić, J., Šubarić, D., Kopjar, M., \& Miličević, B. (2010). Isolation of starch from two wheat varieties and their modification with epichlorohydrin. Carbohydrate Polymers, 81(1), 76-82. http:// dx.doi.org/10.1016/j.carbpol.2010.01.058.

Ahmadi-Abhari, S., Woortman, A., Hamer, R., \& Loos, K. (2015). Rheological properties of wheat starch influenced by amyloselysophosphatidylcholine complexation at different gelation phases. Carbohydrate Polymers, 122, 197-201. http://dx.doi.org/10.1016/j. carbpol.2014.12.063. PMid:25817659.

Ai, Y., \& Jane, J. (2015). Gelatinization and rheological properties of starch. Starch, 67(3-4), 213-224. http://dx.doi.org/10.1002/star.201400201.

Alcázar-Alay, S., \& Meireles, M. (2015). Physicochemical properties, modifications and applications of starches from different botanical sources. Food Science and Technology, 35(2), 215-236. http://dx.doi. org/10.1590/1678-457X.6749.

Barrera, G. N., Bustos, M. C., Iturriaga, L., Flores, S. K., Leon, A. E., \& Ribotta, P. D. (2013). Effect of damaged starch on the rheological properties of wheat starch suspension. Journal of Food Engineering, 116(1), 233-239. http://dx.doi.org/10.1016/j.jfoodeng.2012.11.020.

Bocharnikova, I., Wasserman, L. A., Krivandin, A. V., Fornal, J., Aszczak, W. B., Chernykh, V. Y., Schiraldi, A., \& Yuryev, V. P. (2003). Structure and thermodynamic melting parameters of wheat starches with different amylose content. Journal of Thermal Analysis and Calorimetry, 74(3), 681-695. http://dx.doi.org/10.1023/B:JTAN.0000011001.02981.88.

Dhaka, V., \& Khatkar, B. S. (2015). Effects of gliadin/glutenin and HMW-GS/LMW-GS ratio on dough rheological properties and bread-making potential of wheat varieties. Journal of Food Quality, 38(2), 71-82. http://dx.doi.org/10.1111/jfq.12122.

Elvers, B., \& Ullmann, F. (2017). Ullmann's food and feed. Weinheim: John Wiley \& Sons.

Eriksson, E., Koch, K., Tortoe, C., Akonor, P., \& Baidoo, E. (2014). Physicochemical, functional and pasting characteristics of three varieties of cassava in wheat composite flours. British Journal of Applied Science and Technology, 4(11), 1609-1621. http://dx.doi. org/10.9734/BJAST/2014/7987.

Ghodke, S., Ananthanarayan, L., \& Rodrigues, L. (2009). Use of response surface methodology to investigate the effects of milling conditions on damaged starch, dough stickiness and chapatti quality. Food Chemistry, 112(4), 1010-1015. http://dx.doi.org/10.1016/j. foodchem.2008.05.036.

Gupta, M., Bawa, A., \& Semwal, A. (2009). Morphological, thermal, pasting, and rheological properties of barley starch and their blends. International Journal of Food Properties, 12(3), 587-604. http://dx.doi. org/10.1080/10942910801947763.

Hasjim, J., Ai, Y., \& Jane, J. (2013). Novel applications of amylose-lipid complex as resistant starch type 5. In Y. C. Shi \& C. C. Maningat. Resistant starch: Sources, applications and health benefits (pp. 79-94). Weinheim: John Wiley \& Sons. http://dx.doi.org/10.1002/9781118528723.ch4.

Hoover, R. (2001). Composition, molecular structure, and physicochemical properties of tuber and root starches: a review. Carbohydrate Polymers, 45(3), 253-267. http://dx.doi.org/10.1016/S0144-8617(00)00260-5.

Horstmann, S., Lynch, K., \& Arendt, E. (2017). Starch characteristics linked to gluten-free products. Foods, 6(4), 29. http://dx.doi. org/10.3390/foods6040029. PMid:28383504.
Jan, R., Saxena, D., \& Singh, S. (2016). Pasting, thermal, morphological, rheological and structural characteristics of Chenopodium (Chenopodium album) starch. Lebensmittel-Wissenschaft + Technologie, 66, 267-274. http://dx.doi.org/10.1016/j.lwt.2015.10.040.

Kawai, K., Takato, S., Sasaki, T., \& Kajiwara, K. (2012). Complex formation, thermal properties, and in-vitro digestibility of gelatinized potato starch-fatty acid mixtures. Food Hydrocolloids, 27(1), 228234. http://dx.doi.org/10.1016/j.foodhyd.2011.07.003.

Khan, M., Ahmed, R., Ali, R., \& Sayeed, S. (2015). Relationship of sodium carbonate SRC with some physicochemical, rheological and gelatinization properties of flour and its impact on end quality of biscuit. International Journal of Scientific Research (Ahmedabad, India), 5(8), 1-8.

Kim, H. S., \& Huber, K. C. (2010). Physicochemical properties and amylopectin fine structures of A- and B-type granules of waxy and normal soft wheat starch. Journal of Cereal Science, 51(3), 256-264. http://dx.doi.org/10.1016/j.jcs.2009.11.015.

Koehler, P., \& Wieser, H. (2012). Chemistry of cereal grains. In M. Gobbetti \& M. Gänzle. Handbook on Sourdough Biotechnology (pp. 11-45). US: Springer.

Kweon, M., Slade, L., \& Levine, H. (2011). Solvent Retention Capacity (SRC) testing of wheat flour: Principles and value in predicting flour functionality in different food processes and in wheat breeding - A review. Cereal Chemistry, 88(6), 537-552. http://dx.doi.org/10.1094/ CCHEM-07-11-0092.

Lee, M., Swanson, B., \& Baik, B. (2001). Influence of amylose content on properties of wheat starch and breadmaking quality of starch and gluten blends. Cereal Chemistry, 78(6), 701-706. http://dx.doi. org/10.1094/CCHEM.2001.78.6.701.

Li, W., Shan, Y., Xiao, X., Luo, Q., Zheng, J., Ouyang, S., \& Zhang, G. (2013). Physicochemical properties of A- and B-starch granules isolated from hard red and soft red winter wheat. Journal of Agricultural and Food Chemistry, 61(26), 6477-484. http://dx.doi.org/10.1021/ jf400943h. PMid:23756853.

Lindgren, A., \& Simsek, S. (2015). Evaluation of hard red spring wheat mill stream fractions using solvent retention capacity test. Journal of Food Processing and Preservation, 40(2), 131-139. http://dx.doi. org/10.1111/jfpp.12590.

Marta, H., \& Tensiska, T. (2017, November 23). Functional and amylographic properties of physically-modified sweet potato starch. In M. Muhaemin, Y. Hidayat and H. A. W. Lengkey. 2nd International Conference on Sustainable Agriculture and Food Security: A Comprehensive Approach (pp. 689-700) Indonesia: Universitas Padjadjaran, KnE Life Sciences.

Noda, T., Tsuda, S., Mori, M., Takigawa, S., Matsuura-Endo, C., Saito, K., Mangalika, W. H. A., Hanaoka, A., Suzuki, Y., \& Yamauchi, H. (2004). The effect of harvest dates on the starch properties of various potato cultivars. Food Chemistry, 86(1), 119-125. http:// dx.doi.org/10.1016/j.foodchem.2003.09.035.

Noranizan, M. A., Dzulkifly, M. H., \& Russly, A. R. (2010). Effect of heat treatment on the physicochemical properties of starch from different botanical sources. International Food Research Journal, 17, 127-135.

Oh, H., Hemar, Y., Anema, S., Wong, M., \& Pinder, D. N. (2008). Effect of high-pressure treatment on normal rice and waxy rice starch-inwater suspensions. Carbohydrate Polymers, 73(2), 332-343. http:// dx.doi.org/10.1016/j.carbpol.2007.11.038.

Oke, M., Awonorin, S., \& Workneh, T. (2013). Effect of varieties on physicochemical and pasting characteristics of water yam flours and starches. Journal of Biotechnology, 12(11), 1250-1256. 
Pérez, S., \& Bertoft, E. (2010). The molecular structures of starch components and their contribution to the architecture of starch granules: A comprehensive review. Starch, 62(8), 389-420. http:// dx.doi.org/10.1002/star.201000013.

Pfister, B., \& Zeeman, S. C. (2016). Formation of starch in plant cells. Cellular and Molecular Life Sciences, 73(14), 2781-2807. http://dx.doi. org/10.1007/s00018-016-2250-x. PMid:27166931.

Ragab, K. E., \& Mohamed, A. M. (2014). Screening and genetical study for bread wheat gluten strength using solvent retention capacity (SRC) test. Alexandria Journal of Agricultural Research, 59(3), 189-196.

Ratnayake, W., Otani, C., \& Jackson, D. S. (2009). DSC enthalpic transitions during starch gelatinisation in excess water, dilute sodium chloride, and dilute sucrose solutions. Journal of the Science of Food and Agriculture, 89(12), 2156-5163. http://dx.doi.org/10.1002/jsfa.3709.

Saeed, F., Arshad, M., Pasha, I., Suleria, H., Arshad, M., Qamar, A., Ullah, A., \& Sultan, S. (2014). Effect of arabinoxylan and arabinogalactan on textural attributes of bread. Journal of Food Processing and Preservation, 39(6), 1070-1088. http://dx.doi.org/10.1111/jfpp.12322.

Sarker, M. Z. I., Elgadir, M. A., Ferdosh, S., Akanda, M. J. H., Aditiawati, P., \& Noda, T. (2012). Rheological behavior of starch-based biopolymer mixtures in selected processed foods. Starch, 00, 1-9.

Shevkani, K., Singh, N., Bajaj, R., \& Kaur, A. (2016). Wheat starch production, structure, functionality and applications-a review. International Journal of Food Science \& Technology, 52(1), 38-58. http://dx.doi.org/10.1111/ijfs.13266.

Shewry, P., \& Hey, S. (2015). The contribution of wheat to human diet and health. Food and Energy Security, 4(3), 178-202. http://dx.doi. org/10.1002/fes3.64. PMid:27610232.

Sissons, M. (2016). Durum wheat chemistry and technology. Elsevier Science: Amsterdam.

Sramkova, Z., Gregova, E., \& Sturdik, E. (2009). Chemical composition and nutritional quality of wheat grain. Acta Chimica Slovenica, 2(1), 115-138.

Thachil, M., Chouksey, M., \& Gudipati, V. (2013). Amylose-lipid complex formation during extrusion cooking: Effect of added lipid type and amylose level on corn-based puffed snacks. International Journal of Food Science \& Technology, 49(2), 309-316. http://dx.doi. org/10.1111/ijfs.12333.

Vermeylen, R., Goderis, B., Reynaers, H., \& Delcour, J. (2005). Gelatinisation related structural aspects of small and large wheat starch granules. Carbohydrate Polymers, 62(2), 170-181. http:// dx.doi.org/10.1016/j.carbpol.2005.07.021.

Wani, A. A., Singh, P., Shah, M. A., Wani, I. A., Gotz, A., Schott, M., \& Zacherl, C. (2013). Physicochemical, thermal and rheological properties of starches isolated from newly released rice cultivars grown in Indian temperate climates. Lebensmittel-Wissenschaft + Technologie, 53(1), 176-183. http://dx.doi.org/10.1016/j.lwt.2013.02.020.

Waterschoot, J., Gomand, S., Fierens, E., \& Delcour, J. (2014). Production, structure, physicochemical and functional properties of maize, cassava, wheat, potato and rice starches. Starch, 67(1-2), 14-29. http://dx.doi.org/10.1002/star.201300238.

Wickramasinghe, H., Miura, H., Yamauchi, H., \& Noda, T. (2005), Comparison of the starch properties of Japanese wheat varieties with those of popular commercial wheat classes from the USA, Canada and Australia. Food Chemistry, 93(1), 9-15. http://dx.doi. org/10.1016/j.foodchem.2004.08.049.

Xiao, Z., Park, S., Chung, O., Caley, M., \& Seib, P. (2006). Solvent retention capacity values in relation to hard winter wheat and flour properties and straight-dough breadmaking quality. Cereal Chemistry, 83(5), 465-471. http://dx.doi.org/10.1094/CC-83-0465.

Yin, L., \& Wang, C. (2016). Morphological, thermal and physicochemical properties of starches from squash (Cucurbita maxima) and pumpkin (Cucurbita moschata). Journal of Horticulture, 3(04), 187. http:// dx.doi.org/10.4172/2376-0354.1000187.

Yu, S., Ma, Y., Menager, L., \& Sun, D. (2010). Physicochemical properties of starch and flour from different rice cultivars. Food and Bioprocess Technology, 5(2), 626-637. http://dx.doi.org/10.1007/s11947-0100330-8.

Zeng, J., Li, G., Gao, H., \& Ru, Z. (2011). Comparison of A and B starch granules from three wheat varieties. Molecules (Basel, Switzerland), 16(12), 10570-10591. http://dx.doi.org/10.3390/molecules161210570. PMid:22183883.

Zhang, B., Li, X., Liu, J., Xie, F., \& Chen, L. (2013). Supramolecular structure of A- and B-type granules of wheat starch. Food Hydrocolloids, 31(1), 68-73. http://dx.doi.org/10.1016/j.foodhyd.2012.10.006.

Zhang, C., Zhu, L., Shao, K., Gu, M., \& Liu, Q. (2012). Toward underlying reasons for rice starches having low viscosity and high amylose: Physiochemical and structural characteristics. Journal of the Science of Food and Agriculture, 93(7), 1543-1551. http://dx.doi.org/10.1002/ jsfa.5987. PMid:23238952.

Zhang, W., Gu, J., Wang, Z., Wei, C., Yang, J., \& Zhang, J. (2017). Comparison of structural and functional properties of wheat starch under different soil drought conditions. Scientific Reports, 7(1), 1-18. http://dx.doi.org/10.1038/s41598-017-10802-3. PMid:28951617.

Zhang, Y., Guo, Q., Feng, N., Wang, J., Wang, S., \& He, Z. (2016). Characterization of A- and B-type starch granules in Chinese wheat cultivars. Journal of Integrative Agriculture, 15(10), 2203-2214. http:// dx.doi.org/10.1016/S2095-3119(15)61305-3. 